\title{
Prenatal Stress Up-Regulated Hippocampal Glucocorticoid Receptor Expression in Female Adult Rat Offspring
}

\author{
Estrés Prenatal Expresión del Receptor de Glucocorticoides del Hipocampo \\ Regulado por Aumento en Crías de Ratas Hembras Adultas
}

Libin Liao'; Xueping Yao³ ${ }^{3}$ Jufang Huang ${ }^{2}$ \& Shengbin Bai ${ }^{1}$

LIAO, L.; YAO, X.; HUANG, J. \& BAI, S. Prenatal stress up-regulated hippocampal glucocorticoid receptor expression in female adult rat offspring. Int. J. Morphol., 38(2):400-405, 2020.

SUMMARY: Accumulating evidence from preclinical and clinical studies indicates prenatal exposure to stress or excess glucocorticoids can affect offspring brain. Glucocorticoid receptor (GR) is an important target of glucocorticoid. Therefore the aim of the present study was to investigate the expression of GR in prenatally stressed adult offspring and the relationship between GR expression and behavior in offspring. Pregnant rats received restraint stress during the last week of pregnancy. Hippocampal glucocorticoid receptor expression levels in the offspring were detected on postnatal 60 (P60).Cognition function was also detected. It shows significantly lower hippocampal GR expression was observed in female prenatally stressed offspring compared with their controls at P60. Corresponding to the expression of GR, female prenatally stressed offspring exhibited poorer spatial learning and memory abilities in the Barnes maze than control, This suggests that cognitive impairment in prenatally stressed rat offspring attribute lower hippocampal GR expression.

KEY WORDS: Prenatal stress; Cognitive impairment; Glucocorticoid receptor; Hippocampus.

\section{INTRODUCTION}

Early life events have long lasting impacts on tissue structure and function. Pregnancy is a specific time in a woman's life. During pregnancy, any external environmental influences such as maternal psychological stress not only affect the mother's health but also have lifelong consequences for her developing unborn (Rakers et al., 2017). Prenatal stress is a public health problem that has been reported in $10 \%-35 \%$ of children worldwide (Markham \& Koenig, 2011). It is now widely recognized that exposure to an adverse environment during pregnancy is associated with an adverse pregnancy outcome and increases the individual's risk to develop neurobehavioral disorders, including depression, attention deficit hyperactivity disorder and schizophrenia (Markham \& Koenig; Walker et al., 2008; Ronald et al., 2011; McEwen et al., 2011) cardiovascular and metabolic disease in later life.
A major mechanism to explain the association between adverse prenatal stress and postnatal health is overexposure to glucocorticoids. During the process of prenatal stress, over-activation of a pregnant mother's hypothalamo-pituitary adrenal (HPA) axis, produces excess maternal glucocorticoids and affects the structure and the function of the brains of the offspring. However, currently, little is known about the underlying molecular mechanisms by which excess maternal glucocorticoid levels affect the brains of offspring (Pallarés et al., 2017).

The glucocorticoid receptor is the target of glucocorticoids, It is an important modulators in HPA axis activation response to stress. Importantly, GR is expressed at high levels in the fetal brain of many species, including humans (Moisiadis et al., 2014). Liu et al. (1997) showed that in rats, exposure to high levels of postnatal care leads to

\footnotetext{
${ }^{1}$ Department of Histology and Embryology, Basic Medical College of Xinjiang Medical University, Ürümqi, Xinjiang, P.R.China.

${ }^{2}$ Department of Anatomy and Neurobiology, Central South University School of Basic Medical Sciences, Changsha, Hunan, P.R. China.

${ }^{3}$ Department of Mechanism Lab Centre, Basic Medical College of Xinjiang Medical University, Ürümqi, Xinjiang, P.R. China.

FUNDING: This research was supported by grants from the National Natural Science Foundation of China (No.81871089); the University Research Program of Xinjiang (XJEDU2018Y027); Student Research Training Program of Xinjiang Medical University (CX2019060).
} 
increase GR mRNA expression in the hippocampus and reduced HPA axis response to restraint stress as adults compared with offspring raised by low licking-grooming dams. Human studies also indicated hippocampal GR targets might be subjected to programming by early life events (Cottrell \& Seck, 2009). These results indicated that glucocorticoid receptor may has associated with behavioural outcomes influenced by prenatal stress. Therefore, the objective of the present study is to analyze the effects of prenatal stress in the expression of glucocorticoid receptor in hippocampus of adult offspring.

\section{MATERIAL AND METHOD}

Animals. Adult female Sprague-Dawley rats (250-300 g) were used in this study. They were housed in an animal care facility within the Department of Laboratory Animals in Central South University, Hunan, P.R. China, under stable temperature $\left(22 \pm 1^{\circ} \mathrm{C}\right)$ and lighting conditions (12-h light/ 12 -h dark cycle). Food and water were provided, along with constant care and clean conditions.

All animal experiments were conducted in accordance with the National Institute of Health Guide for the Care and Use of Laboratory Animals (NIH Publications No. 80-23), revised in 1996, and were approved by the Animal Ethics Committee of the Third Xiangya Hospital (Changsha, China). All efforts were taken to minimize the number, suffering, and discomfort of all laboratory animals used in this study.

Prenatal stress procedure. Pregnant females were housed individually and were randomly assigned to a stressed $(\mathrm{n}=$ $6)$ or control $(n=6)$ group. The prenatal stress protocol was adapted from previous studies and was performed at the last week of pregnancy. Pregnant dams were placed into transparent plastic restrainers $(8.6 \mathrm{~cm}$ in diameter $\times 21.6 \mathrm{~cm}$ in length) at 09:00 h, 13:00 h, and 17:00 h for 45 min daily. Control dams were left undisturbed in their home cages. After birth, the pups were raised with their mothers. The offspring were weaned on postnatal day 21 and group-housed with littermates of the same sex.

Behavioral analysis. The Barnes maze was used to test the spatial learning and memory abilities of the subjects. This test was performed as previously described (Barnes, 1979). The maze used in the present study was a white, circular disk (122 cm in diameter) with 18 holes $(9.5 \mathrm{~cm}$ in diameter, placed every $20^{\circ}$, and close to the edge of the disk) and a high stand (140 cm height) supporting the disk. The first trial was the habituation phase. Each rat was placed in a cylindrical black start chamber in the middle of the maze. After $15 \mathrm{~s}$ had elapsed, the chamber was lifted. Then, the rat was exposed to a bright light and gently guided to the escape box. The rat was allowed 3 min to search for the escape box following stimulation with the same light. If the rat failed to locate the escape box, it was gently guided to the box. Once the rat was inside the box, the light was turned off, and the rat was permitted to stay in the escape box for 2 min. The entry hole in the box was covered with a black sheet. The spatial location of the target box and the corresponding hole were relatively fixed over the 4-day test ( 3 trials/day), as were the spatial cues in the room. The rat was then returned to its home cage for a 15-min interval before the next trial. Between each trial, the surface of the disk was cleaned with $75 \%$ ethanol to remove any potential odor cues. The escape latency for reaching the target hole and the escape errors were recorded and compared.

Tissue collection. Rats were sacrificed via decapitation after anesthetization with $5 \%$ sevoflurane, and whole brains (including the entire hippocampus) were quickly removed. The brain tissues used for immunostaining were post-fixed with $4 \%$ paraformaldehyde for $24 \mathrm{~h}$ at $4^{\circ} \mathrm{C}$. The tissues were then sequentially placed in $15 \%$ and $30 \%$ sucrose in $0.1 \mathrm{M} \mathrm{PBS}$ at $4^{\circ} \mathrm{C}$. Next, the brain tissues were embedded in Tissue-Tek optimal cutting temperature medium (Sakura Finetek Japan Co. Ltd. Tokyo) frozen in liquid nitrogen, and stored at $-80{ }^{\circ} \mathrm{C}$. For Western blot analysis, samples of the entire hippocampus were immediately isolated, frozen in liquid nitrogen and stored at $-80{ }^{\circ} \mathrm{C}$.

Western blot analysis. Proteins were extracted from the hippocampal regions. Protein concentrations were determined using a bicinchoninic acid (BCA) protein assay kit (CWBio, China). Proteins $(40 \mu \mathrm{g})$ were separated on 8 $\%$ denaturing acrylamide gels (SDS-PAGE) and transferred to membranes. The membranes were incubated with rabbit monoclonal rabbit monoclonal anti-GR (1:1000; Proteintech Group) antibodies. After rinsing with Tris-buffered saline (Sigma.USA) containing $0.3 \%$ Tween-20(Beijing solarbio science technology Co. Ltd. Beijing, China), the membranes were incubated with an IRDye ${ }^{\circledR} 800 \mathrm{CW}$ goat anti-rabbit secondary antibody (1:8000; 926-32211, Li-COR®, USA) for $1 \mathrm{~h}$ at room temperature.

After washing, the immunoblotted bands were visualized using an Odyssey-CLX infrared imaging system (Li-COR®). GAPDH was used to normalize protein levels as an internal reference control. The integrated density values of specific proteins were quantified using Image $J$ software (National Institutes of Health, MD, USA), and the relative expression levels of the proteins were normalized by calculating the ratio of the target proteins (GR) to GAPDH. 
Immunohistochemistry. The hippocampal tissues were serially cut into $20 \mathrm{~mm}$ thick sections on a freezing sliding microtome (Leica CM1950, Leica, Germany). Free-floating sections of hippocampal tissues were washed with PBS (Sinopharm Group.Co.Ltd.Beijing.China) and then sequentially treated with $3 \%$ hydrogen peroxide (Sinopharm Group Co. Ltd) in $0.01 \mathrm{M}$ PBS for $10 \mathrm{~min}$ and $5 \%$ bovine serum albumin (BSA, Sigma, MO, USA) in 0.01 M PBS containing $0.3 \%$ Triton X-100 (Beijing solarbio science technology Co.Ltd) for $1 \mathrm{~h}$. Next, the tissue sections were incubated with a polyclonal rabbit anti-GR antibody (1:200; Proteintech Group, Wuhan.China) overnight at $4^{\circ} \mathrm{C}$. Then, the sections were washed with PBS and subsequently exposed to the corresponding biotinylated secondary antibody (1:200; Vector Laboratories, USA). After a 1-h incubation with avidin-biotin complex reagents ( $\mathrm{ABC}$ Elite Kit, Vector Laboratories, USA), the immunoreaction products were visualized using DAB kits (Beijing Zhongshan Jinqiao Biological Technology Co., Ltd, China). Finally, the floating sections were mounted, dehydrated, cleared, and coverslipped in PermountTM mounting medium (Sinopharm Group.Co.Ltd). Photographs were captured under a microscope (Nikon, Tokyo, Japan) and analyzed.

Statistical analysis. The data are presented as means \pm standard errors (means \pm SEM), and statistical graphs were processed using GraphPad Prism 5.0 software (GraphPad Software Inc., La Jolla, CA, USA) and Adobe Photoshop CS4 software (Adobe Systems Incorporated, CA, USA). The results of the Barnes maze test were analyzed with repeatedmeasures ANOVA using SPSS version 19.0 (SPSS Inc., Chicago, IL, USA). Other results were statistically analyzed using unpaired Student's t-tests. $\mathrm{P}<0.05$ was considered statistically significant.

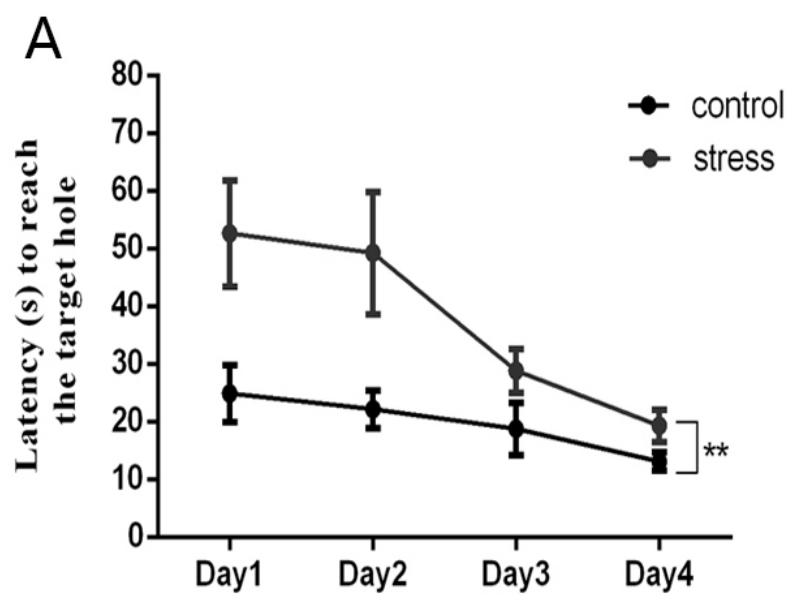

\section{RESULTS}

Prenatal stress reduced birth weight. We detected the weight of the females offspring on postnatal 0 day, compared to control offspring group, the birth weight significantly decreased in the prenatally stressed adult offspring $(\mathrm{t}=7.035$, $\mathrm{P}<0.001)$.

Prenatal stress impaired the spatial learning and memory abilities of adult offspring. Regarding the Barnes maze test, data were analyzed using repeated-measures ANOVA. Compared to the control offspring, the latency to

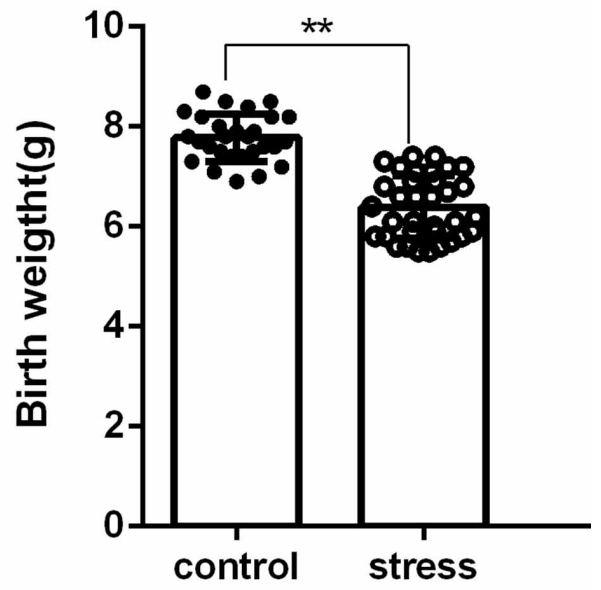

Fig. 1. Weight of the offspring on postnatal 0 day, Data are expressed as means \pm SEM. ** $\mathrm{P}$ $<0.005$ compared with the control, as measured by t-tests $(\mathrm{n}=28$ per group). control: normal offspring, stress: prenatally stressed offspring.

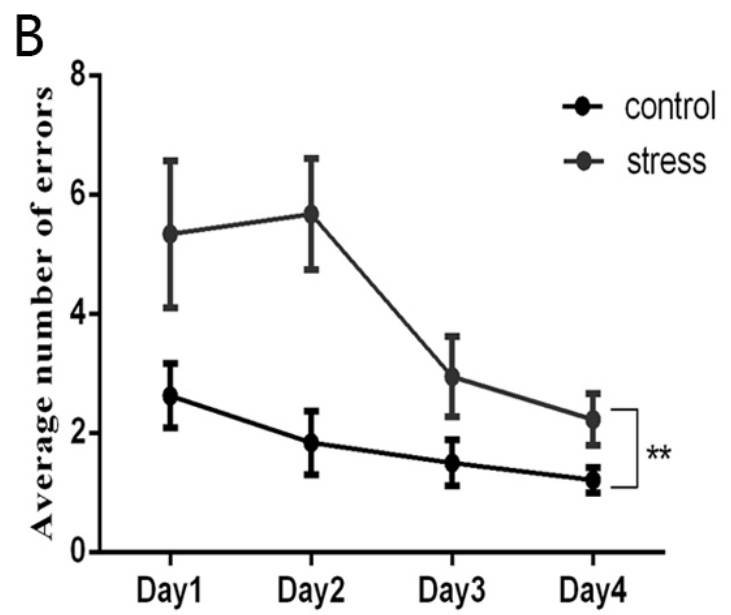

Fig. 2. Prenatal stress causes abnormal behavior in adult female offspring. A The latency to reach the target hole is increased in the female prenatally stressed offspring $(\mathrm{F}(1,14)=3.640, \mathrm{P}=0.008$ as measured by repeated-measures ANOVA). B Female prenatally stressed offspring committed a significantly greater number of errors than control female offspring $(F(1,14)$ $=17.015, \mathrm{P}=0.001$, as measured by repeated-measures ANOVA).control: normal offspring, stress: prenatally stressed offspring. 


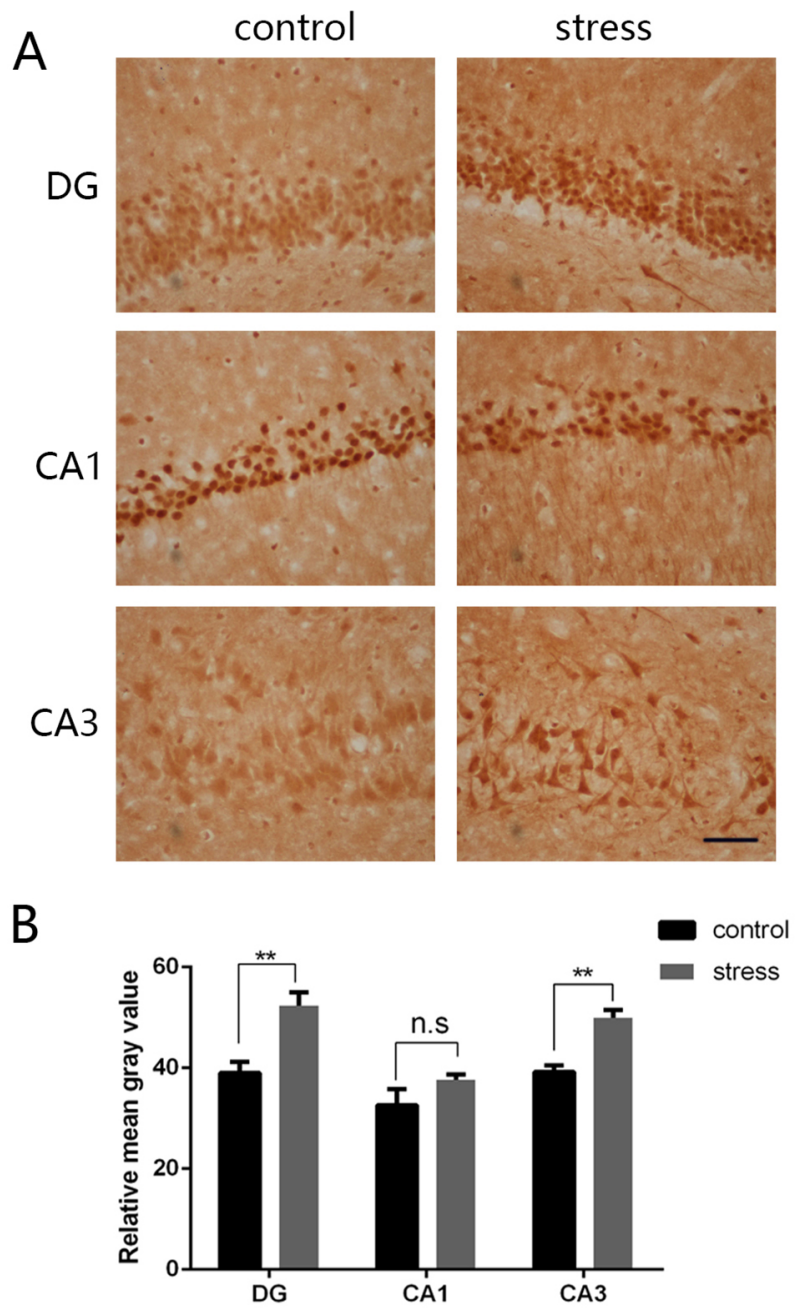

Fig. 3. Hippocampal GR expression in the female offspring on postnatal day 60. (A) Representative images of GR immunostaining in the hippocampus of P60 female offspring from 3 different mothers subjected to prenatal restraint stressor or control conditions. Scale bar $=50 \mathrm{~mm}$. (B) A quantification analysis of immunohistochemistry in DG, CA1 and CA3 in the hippocampus of P60 female offspring (DG: $\mathrm{T}=3.386, \mathrm{p}=0.0012$; CA1: $\mathrm{T}=$ $1.233, \mathrm{p}=0.057 ; \mathrm{CA} 3: \mathrm{T}=3.556, \mathrm{p}=0.0119)$ Data are expressed as the means \pm SEM. $* * P<0.05$, as measured by unpaired t-test ( $\mathrm{n}$ $=6$ per group).control: normal offspring, stress: prenatally stressed offspring.

reach the target hole is increased in the female prenatally stressed offspring $(\mathrm{F}(1,14)=3.640, \mathrm{P}=0.008$ Fig. 2A). Female prenatally stressed offspring committed a significantly greater number of errors than did the control female offspring $(\mathrm{F}(1,14)=17.015, \mathrm{P}=0.001 \mathrm{Fig}$. $2 \mathrm{~B})$.

Prenatal stress up-regulated hippocampal GRs expression in prenatally stressed adult offspring. We detected hippocampal GR expression in the offspring from 3 pairs of
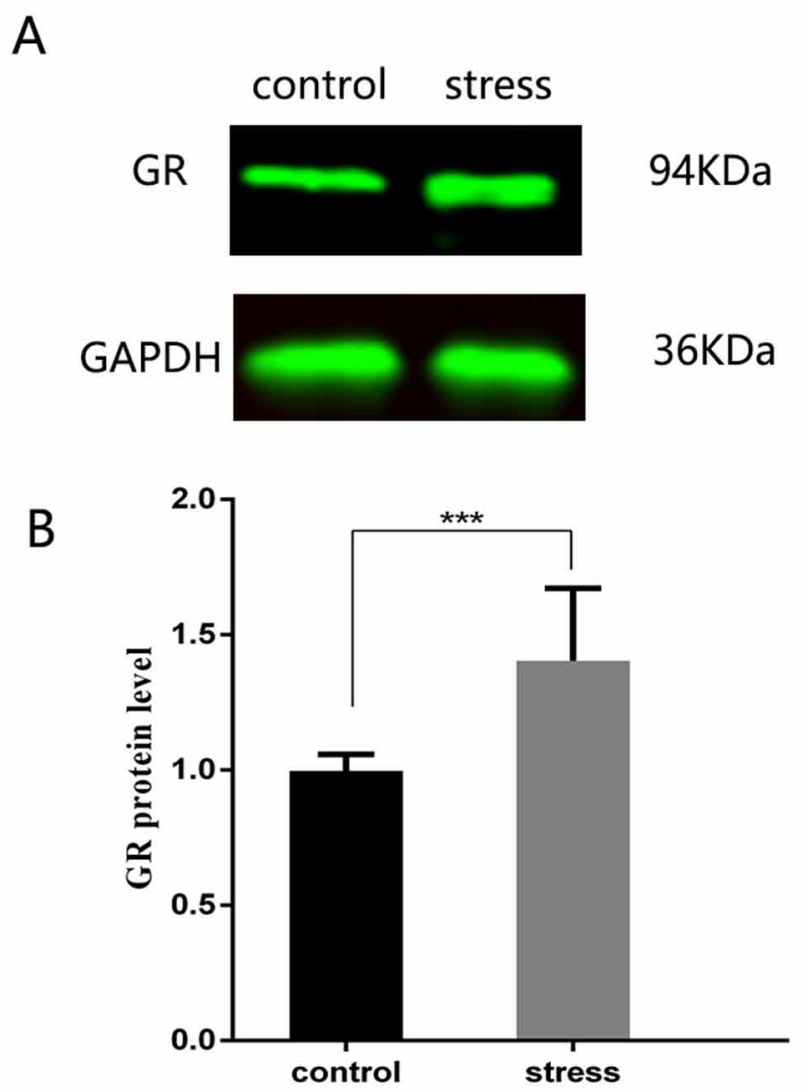

Fig. 4. Western blot analysis of GR levels in the hippocampus. Western blot analysis of hippocampal GR levels in P60 offspring from 3 pairs of pregnant rats subjected to prenatal restraint stress or control conditions. Data are expressed as the means \pm SEM. $* * * \mathrm{P}<0.05$, as measured by unpaired $\mathrm{t}$-test $(\mathrm{n}=6$ per group). control: normal offspring, stress: prenatally stressed offspring.

pregnant rats subjected to prenatal restraint stress or control conditions. On P60, hippocampal GRs expression in the female prenatally stressed offspring was significantly increased in DG and CA3 area, but no difference in CA1 area compared to that in control offspring $(\mathrm{DG}: \mathrm{T}=3.386, \mathrm{p}$ $=0.0012 ; \mathrm{CA} 1: \mathrm{T}=1.233, \mathrm{p}=0.057 ; \mathrm{CA} 3: \mathrm{T}=3.556, \mathrm{p}=$ 0.0119 , Fig. 3). Western blot analysis also showed on P60, significantly higher hippocampal GR expression was observed in female prenatally stressed offspring than in control female offspring ( $\mathrm{T}=7.400, \mathrm{P}=0.0100$ Fig. 4).

\section{DISCUSSION}

Prenatal stress transmits its affect on developing fetus and on pregnancy outcomes in adult offspring (Weinstock, 2017).Many studies have shown that administered with 
glucocorticoids during pregnancy reduces birth weight and that these offspring are at risk of HPA axis perturbations. We analyzed the changes in birth weight and behavior. In our study, the birth weight significantly decreased in the prenatally stressed adult offspring. This is consistent with previous literature. Low birth weight as an indicator of a suboptimal intrauterine environment and a predictor of later disease risk. We also detected the spatial learning in female offspring, Previous experiments were performed only in males and showed impaired spatial learning in adulthood (Weinstock, 2015). In our study, It showed female prenatally stressed adult offspring also exhibited poorer spatial learning and memory abilities.

Glucocorticoids is considered to be the most important mediators to transmit prenatal stress affect to the offspring. Thus, A large number of studies have confirmed elevated levels of glucocorticoids in the prenatally stressed offspring (Nicolaides et al., 2015; van Bodegom et al., 2017). We also have detected high glucocorticoids in offspring in previous (Liao et al., 2019). Meanwhile, Exposure of the fetus to stress or high levels of glucocorticoids-whether from exogenous or endogenous origins can permanently affect GR expression (Levitt et al., 1996). The GR expression in female offspring hippocampus may involve in the prenatal stress outcome.

During development, GR are expressed from early embryonic life in most tissues. Glucocorticoid receptors are essential for offspring survival, as indicated by the lethal postnatal phenotype of GR null mice (Cole et al., 1995). GR overexpressing animals produces mice with a relatively stress resistant phenotype (Reichardt et al., 2000; Wei, et al., 2004). In the rat there is a relatively high expression of GR from midgestation onwards (Diaz et al., 1998) and a rapid rise in GR expression after birth (Matthews et al., 2002). Hence, the last week of gestation and early postnatal life are considered particularly sensitive periods in rodent development in terms of glucocorticoid mediated programming. In our study, prenatal stress was performed at the last week of gestation. Thus On P60, hippocampal GR expression in the female prenatally stressed offspring was significantly increased compared to that in control offspring. GR in the brain leads to feedback inhibition of the maternal and fetal HPA axis and a reduction in levels of cortisol (or corticosterone). Therefore, higher GR expression in the prenatally stressed offspring hippocampus and reduced HPA axis responses to stress. In guinea-pigs, prenatal dexamethasone exposure results in significant increases in GR mRNA in the CA1-2 region of the hippocampus in female fetuses (Dunn et al., 2010). These results indicated that long-term stress and behavioral outcomes influenced by events in early life, which are associated with HPA axis disturbances.
In conclusion, our findings provide evidence that maternal prenatal stress upregulated hippocampal GR expression in female rat offspring, GR mediates offspring behavioral.

LIAO, L.; YAO, X.; HUANG, J. \& BAI, S. Estrés prenatal expresión del receptor de glucocorticoides del hipocampo regulado por aumento en crías de ratas hembras adultas. Int. J. Morphol, 38(2):400-405, 2020.

RESUMEN: La evidencia acumulada de estudios preclínicos y clínicos indica que la exposición prenatal al estrés, o el exceso de glucocorticoides puede afectar el desarrollo cerebral de las crías. El receptor de glucocorticoides (RG) es un objetivo importante de los glucocorticoides. Por lo tanto, el objetivo del presente estudio fue investigar la expresión de RG en crías adultas estresadas durante el período prenatal y la relación entre la expresión de RG y el comportamiento de las crías. Las ratas preñadas recibieron niveles de estrés restringido, durante la última semana de embarazo. Se determinaron niveles de expresión del receptor de glucocorticoides del hipocampo y niveles de función cognitiva en las crías. En comparación con el grupo control se observó una expresión de RG en el hipocampo, significativamente menor en las crías estresadas prenatalmente, en comparación con los controles en P60. En referencia a la expresión de RG, las crías estresadas prenatalmente exhibieron habilidades de memoria y aprendizaje espacial menores, en el laberinto de Barnes que el grupo control. Esto sugiere que el deterioro cognitivo en crías de ratas estresadas prenatalmente muestran una menor expresión de RG en el hipocampo.

PALABRAS CLAVE: Estrés prenatal; Deterioro cognitivo; Receptor de glucocorticoides; Hipocampo.

\section{REFERENCES}

Barnes, C. A. Memory deficits associated with senescence: a neurophysiological and behavioral study in the rat. J. Comp. Physiol. Psychol., 93(1):74-104, 1979.

Cole, T. J.; Blendy, J. A.; Monaghan, A. P.; Krieglstein, K.; Schmid, W.; Aguzzi, A.; Fantuzzi, G.; Hummler, E.; Unsicker, K. \& Schutz, G. Targeted disruption of the glucocorticoid receptor gene blocks adrenergic chromaffin cell development and severely retards lung maturation. Genes Dev., 9(13):1608-21, 1995.

Cottrell, E. C. \& Seckl, J. R. Prenatal stress, glucocorticoids and the programming of adult disease. Front. Behav. Neurosci., 3:19, 2009.

Diaz, R.; Brown, R. W. \& Seckl, J. R. Distinct ontogeny of glucocorticoid and mineralocorticoid receptor and 11beta-hydroxysteroid dehydrogenase types I and II mRNAs in the fetal rat brain suggest a complex control of glucocorticoid actions. J. Neurosci., 18(7):257080,1998

Dunn, E.; Kapoor, A.; Leen, J. \& Matthews, S. G. Prenatal synthetic glucocorticoid exposure alters hypothalamic-pituitary-adrenal regulation and pregnancy outcomes in mature female guinea pigs. $J$. Physiol., 588(Pt. 5):887-99, 2010.

Levitt, N. S.; Lindsay, R. S.; Holmes, M. C. \& Seckl, J. R. Dexamethasone in the last week of pregnancy attenuates hippocampal glucocorticoid 
receptor gene expression and elevates blood pressure in the adult offspring in the rat. Neuroendocrinology, 64(6):412-8, 1996.

Liao, L.; Wang, X.; Yao, X.; Zhang, B.; Zhou, L. \& Huang, J. Gestational stress induced differential expression of HDAC2 in male rat offspring hippocampus during development. Neurosci. Res., 147:9-16, 2019.

Liu, D.; Diorio, J.; Tannenbaum, B.; Caldji, C.; Francis, D.; Freedman, A.; Sharma, S.; Pearson, D.; Plotsky, P. M. \& Meaney, M. J. Maternal Care, Hippocampal glucocorticoid receptors, and hypothalamic-pituitaryadrenal responses to stress. Science, 277(5332):1659-62, 1997.

Markham, J. A. \& Koenig, J. I. Prenatal stress: role in psychotic and depressive diseases. Psychopharmacology (Berl.), 214(1):89-106, 2011.

Matthews, S. G.; Owen, D.; Banjanin, S. \& Andrews, M. H. Glucocorticoids, hypothalamo-pituitary-adrenal (HPA) development, and life after birth. Endocr. Res., 28(4):709-18, 2002.

McEwen, B. S. \& Gianaros, P. J. Stress- and allostasis-induced brain plasticity. Annu. Rev. Med., 62:431-45, 2011.

Moisiadis, V. G. \& Matthews, S. G. Glucocorticoids and fetal programming part 1: Outcomes. Nat. Rev. Endocrinol., 10(7):391-402, 2014.

Nicolaides, N. C.; Kyratzi, E.; Lamprokostopoulou, A.; Chrousos, G. P. \& Charmandari, E. Stress, the stress system and the role of glucocorticoids. Neuroimmunomodulation, 22(1-2):6-19, 2015.

Pallarés, M. E. \& Antonelli, M. C. Prenatal stress and neurodevelopmental plasticity: relevance to psychopathology. Adv. Exp. Med. Biol., 1015:117-29, 2017

Rakers, F.; Rupprecht, S.; Dreiling, M.; Bergmeier, C.; Witte, O. W. \& Schwab, M. Transfer of maternal psychosocial stress to the fetus. Neurosci. Biobehav. Rev., 2017. Doi: 10.1016/j.neubiorev.2017.02.019. [Online ahead of print]

Reichardt, H. M.; Umland, T.; Bauer, A.; Kretz, O. \& Schutz, G. Mice with an increased glucocorticoid receptor gene dosage show enhanced resistance to stress and endotoxic shock. Mol. Cell. Biol., 20(23):900917, 2000.

Ronald, A.; Pennell, C. E. \& Whitehouse, A. J. O. Prenatal maternal stress associated with ADHD and autistic traits in early childhood. Front. Psychol., 1:223, 2011.

van Bodegom, M.; Homberg, J. R. \& Henckens, M. J. A. G. Modulation of the hypothalamic-pituitary-adrenal axis by early life stress exposure. Front. Cell. Neurosci., 11:87, 2017.

Walker, E.; Mittal, V. \& Tessner, K. Stress and the hypothalamic pituitary adrenal axis in the developmental course of schizophrenia. Annи. Rev. Clin. Psychol., 4:189-216, 2008.

Wei, Q.; Lu, X. Y.; Liu, L.; Schafer, G.; Shieh, K. R.; Burke, S.; Robinson, T. E.; Watson, S. J.; Seasholtz, A. F. \& Akil, H. Glucocorticoid receptor overexpression in forebrain: a mouse model of increased emotional lability. Proc. Natl. Acad. Sci. U. S. A., 101(32):11851-6, 2004.

Weinstock, M. Changes induced by prenatal stress in behavior and brain morphology: can they be prevented or reversed? Adv. Neurobiol., 10:3$25,2015$.

Weinstock, M. Prenatal stressors in rodents: effects on behavior. Neurobiol. Stress, 6:3-13, 2017.

\author{
Corresponding author: \\ Dr. Jufang Huang \\ Department of Anatomy and Neurobiology \\ Central South University School of Basic Medical Sciences \\ Changsha, Hunan \\ CHINA
}

Email: huangjufang@csu.edu.cn

\section{Corresponding author: \\ Dr. Shengbin Bai}

Department of Histology and Embryology

Basic Medical College of Xinjiang Medical University

Ürümqi, Xinjiang

CHINA

Email: bsbxx@a26.com

Received: 04-09-2019

Accepted: 15-10-2019 